\title{
Analysis of the arts and crafts of Tang Dynasty and Song Dynasty
}

\author{
Lu Cheng ${ }^{1}$, Ge Cheng ${ }^{2}$ \\ ${ }^{1}$ ShangHai Publishing and Printing College, China \\ ${ }^{2}$ Shanghai Sibo vocational and Technical college, China
}

Keywords: Gorgeous; Elegant; The Forms Of Arts And Crafts; The Background Of Arts And Crafts.

\begin{abstract}
The art and crafts of Tang Dynasty and Song Dynasty is splendid,Tang is gorgeous and Song is elegant.the forms of arts and crafts is ceramics,silk,clothing, lacquerware,furniture.the modeling of Tang Dynasty and Song Dynasty is refined,the technology is skilled. It is wisdom crystallization of ancient Chinese people. the art and crafts of Tang and Song is shining glorious on the art history.
\end{abstract}

\section{Introduction}

China has a long history of ancient civilization, from the beginning of the primitive society, every era has its brilliant arts and crafts, Shang Dynasty and Zhou Dynasty is famous for bronze art, the sculpture of Qin and Han Dynasties, Tang San Cai is very famouse crafts in Tang Dynasty, Song porcelain is great, Ming dynasty is famouse for furniture, Wood carving and jade art at Qing Dynasty are shining bright brilliant. On the basis of the Tang Dynasty, the Tang Dynasty ruled one China, and it was the richest and powerful country in the world, the vast territory, the political integrity, the commercial development, the frequent exchanges of all ethnic groups, the open culture formed the rich art of the Tang Dynasty. The Song Dynasty on the basis of inheriting the civilization of the Tang Dynasty, under the political background of the heavy text, not only under the influence of the spirit of proving the Neo-Confucianism, formed the art style of the Song Dynasty art art elegant and dignified and concise.

\section{Ceramic}

A variety of arts and crafts of the Tang and Song dynasties ceramics, Tang's ceramic craft is the beginning of China's ceramic technology into the real porcelain era. Tang Dynasty porcelain kiln around the whole country, the Tang Dynasty ceramics is famouse for celadon, white porcelain, Tang San Cai , "South Green North White" refers to the Tang Dynasty white porcelain and celadon. Celadon is the mainstream, celadon is representative of the kiln-Shaoxing, which in the sounth of china. the shape is characterized by thin fetal bones, glazing uniform, glaze warm.Tang Dynasty celadon is green for the beautiful, its enamel color is similar to jade, in the literary language, there are many praise poems of celadon, White porcelain is famouse for Xingzhou kiln in the Hebei Xingtai , white porcelain is another representative of the Tang Dynasty ceramics, Xing kiln porcelain is a great invention of porcelain, if there is no Xing kiln of white porcelain invention, may not there are colorful porcelain world .Its glaze white was green, fine fine, porcelain hard, simple,dignified .In addition, Tang San Cai is famouse of rich glamorous colour and graceful shape, is the Tang Dynasty ceramic works of art unique work. It is a low-temperature lead glazed pottery, with yellow, green and brown-based color for decoration, which is famour of modeling vivid, bright color.

Song porcelain modeling is simple and graceful, elegant and subtle, noble and simple, embodies the Confucian culture advocated by the simple and elegant beauty. Song porcelain in the production scale and production technology, reached a new height.

Song porcelain is the development of China's ceramic industry, in addition to the traditional celadon, white porcelain and black porcelain, there are colourful porcelain and flower glaze porcelain. Ding kiln,Ru kiln,Guan kiln, Ge kiln,Jun kiln, these five kilns is famouse klin of Song dynasty.Ru 
kiln is light blue-based tone and elegant elegance, showing a gentleman of the gentleman style. Jun kiln green with red, kiln change style Yan, showing a changing style. Song porcelain style in the simple and elegant style, smooth lines, elegant and dignified. Song porcelain more decorated dragon, phoenix, deer, cranes, fish, flowers and birds, baby scenes, landscape and other often as the main decoration, with engraved, drawn, tick, painting and sculpture and other different techniques.

\section{Silk}

Tang silk variety, Jin, Luo, yarn, satin, silk, Ling and so on. Tang silk fabric pattern transmited the Han Dynasty fabric of patterns and absorbed foreign patterns and integration, which present the style: rich, free, lively, gorgeous, smooth, with a typical oriental color. Tang silk production throughout the country, which have varify names. Tang Jin as a representative to the latitude from the flowers can be woven complex pattern and gorgeous decorative effect, decorative patterns to the joint as the representative of the beads, absorbing fusion of foreign patterns. Tang is the era of great integration of national culture, Tang dynasty face foreign culture is : tolerant and open attitude, Such as the Byzantine pattern: tree of life, which repeated in the Tang Jin, modeling more complex, the name has changed, the Tang called "flower tree", which reflects the Chinese-style transformation from west to east.

Song silk in addition to the traditional Kam, there are Qi, yarn, Luo, crepe, silk, Ling and so on. To brocade, for example, the Song Dynasty weaving patterns is "four consecutive" ,regardless of pattern design, the color matching, weaving technology is more improve than Tang dynasty.

Song Jin process of production is complex, unique technology, the silk has two, divided into the surface and the under of the layer, so it is called as Kam. Song silk pattern is mainly set up with natural vivid foliage and a large flowers and birds, influence of the era aesthetic ideas, the overall color tends to light and soft, elegant and solemn. Tang Dynasty commonly used in the bright red color is no longer popular, brown, lotus color and other colors as basic colour at Song dynasty, reflecting the Song Dynasty elegant art style.

\section{Clothing}

Tang is an open dynasty, the Tang Dynasty costumes is rich and colorful, magnificent, varied, become a beautiful wonderful flower on the history of Chinese costumes. Tang Dynasty dress is the most sexy aesthetic in the history, Tang women's clothing is popular big shirt sleeves skirt, it is very open, skirt waist high to the chest and long skirt towed elegant, which bring out the Tang Dynasty women graceful, plump, gorgeous posture. Tang female costumew bacome into the most beautiful and opendress at the whole of China's clothing history .tang wear style, that is: the collar opened lower, just the court concubines, dancers wearing, and later became popular between the giants lady , dark red, apricot, purple, green and so on, of which the color is very beautiful, Especially the pomegranate color of the longest time."Hu Fu"is also very popular, "Hu Fu" is the Western clothing. At the same time Tang costumes has a great impact on the neighboring clothing culture, such as Japan's kimono, from the form, color , all draw of the essence of the Tang suit, Korea also inherited the form of Tang clothing.

Song Dynasty constume changed the Tang Dynasty dress of open and luxury style. Song clothing is close to simple and concise, clothing becomes conservative, the color tends to elegant. The costumes were related to the Confucianism in the Northern Song Dynasty .Confucianism advocates simple ideas,in the Song Dynasty fashion trend: the large sleeves shirt, color are more be black and white, the woman dress is straight collar characterized by simple style generous.women's clothing color although inherited the the colour style of Tang Dynasty palace , but no gorgeous wealth compare to Tang, color concentration decreased, into a light and harmonious. Song Dynasty costumes is an innovation to the Tang Dynasty, the natural beauty of clothing, subtle and elegant, is the reflection of its cultural characteristics of the times in Song dynasty. 


\section{Lacquerware}

Tang Dynasty economic developed and cultural prosperity, arts and crafts in the technology and production scale are far ahead of the before.Tang Dynasty lacquerware showing a gorgeous style, Lacquerware varieties have gold and silver pingtuo, painted gold, screw fine, folder and appeared carved lacquer. With the Chinese characteristics of the lacquer craft in the Tang Dynasty there has been a new leap.In the Tang Dynasty appeared on the embossed gold painting technology, the way is in the carved wooden figurines deposited on the black paint or color, and then paint gold lines .

Song lacquer varieties of gold paint, rhinoceros, snail fine, carved lacquer and other varieties. Song lacquer craft simple,the figure is beautiful, the structure,rhythm and propotion is gorgoes, Its characteristics keep one colour, pursuit the simple and elegant lacquer features. Multipurpose petal-shaped mouths are prevailing at the prevailing style, and the curve of change is given it beautiful rhythm. At the same time, the Song Dynasty's Luodian, rhinoceros, gold paint, carved lacquer and other technology also brillant. Throughout the Song Dynasty lacquer art, its characteristics such as Song porcelain, the figure is elegant, plain, natural beauty.

\section{Furniture}

Tang Dynasty when is peroid of sitting on the ground changed to sitting chair, Tang has furniture of sitting down , such as tables, chairs, cases, beds, etc., variety of materials, decorative methods , simple style. To the Song Dynasty furniture structure established to the frame structure as the basic style, furniture layout of a certain style in the interior. Song Dynasty furniture modeling simple and delicate, reasonable structure, Song Dynasty respect nature, simple, standardized, these ideas are reflected on the furniture is a elegant beauty.

\section{Part Two: The Background Of Tang And Song Arts And Crafts}

\subsection{Political and economic}

The development of arts and crafts in the Tang Dynasty was the most prosperous period of feudal society in China. After the "Zhenguanzhizhi" and "Kaiyuan's rule", the Tang and s had gained unprecedented prosperity ,the power of counrty is strong people life is wealthy. The rulers adopted an open and compatible political and cultural policy. The confidence of tang politics, promote of Chinese and foreign culturall exchanges, Tang Dynasty arts and crafts is brilliant, grand, self-confidence, gorgeous artistic characteristics; Song Dynasty in the Liao, Jin and Xia regime forces continue to take The style of art in the lack of Tang's magnificent broad style, but the Song Dynasty arts and crafts with its elegant, plain aesthetic style reflects its unique characteristics of the times .

\subsection{Culture, philosophy}

In the religion, the brilliant Tang Dynasty with a strong economic and political background, on the interpretation, Taoism, Confucianism and respect, and Confucian ethics as a benchmark, Buddhist and Taoist theory of the ruling system, greatly consolidate the imperial foundation, Of the ideological consciousness of liberation, artistic expression without taboos, the language is more free, in the arts and crafts on the decoration of a fresh and free style. At the same time, the Tang Dynasty attaches importance culture and education, pay attention to personnel training, advocate the development of science and technology culture. With a free and open confidence to accept the Quartet culture. This series of measures to make Tang culture in various fields flourishing.Science and technology, medicine, literary poetry, prose, painting, arts and crafts and other fields, has made brilliant achievements. Song Dynasty in the field of philosophy, science dominates. Neo-Confucianism put forward the "survival of heaven, eliminate desires" a direct impact on the Song Dynasty's artistic style. In the literature and art, against the blossom gorgeous words, the pursuit of poetry to plain, smooth language as the goal. Ouyang Xiu advocated poetry reform movement, to promote the simple style, to 
plain as the highest aesthetic ideal of literature. This kind of implicit and light, Wen Shouli fine style of the wind on the Soviet Union, Lu You had a great impact. This elegant style will naturally have an impact on painting, arts and crafts. In this kind of introverted depression under the guidance of philosophy, under the influence of the style of worship, the Song Dynasty arts and crafts regardless of porcelain, silk, lacquerware, furniture show a simple light beauty.

\subsection{The Influence of folk culture}

Tang built on dynasty which the combined with WeiJin ,north and south dynasty after many wars years and conflict with culture.influenced by social customs of ethnic minorities, there has north people of character with rebellious. Tang people like riding, hunting, polo and other entertainment,as the life impacted by north culture, the culture of Tang is up,strong,,vibrant compare to Song dynasty weak scholary Culture. Reflected on the culture, Tang's literature must have poetic romantic of Libai. reflected in the painting which lines must have character of the wind elegant style; reflected in the calligraphy must have master Zhang Xu wild unruly; reflected in the Art and crafts must have a gorgeous grace of the posture. At the same time the Tang Dynasty arts and crafts language of nature, life, full of rich life taste, giving freedom, unrestrained, lively beauty. Chinese people like the rich, full of performance techniques, like curly lines, peony flowers as decorative patterns. To the life style as an artistic theme, such as travel, pleasure, polo, etc ; Song Dynasty commodity economy is highly prosperous, the emerging status of the city citizen class rise, the rise of secular culture in the Song Dynasty. Its arts and crafts style, gradually from gorgous into practical, simple style. Song Dynasty arts and crafts theme is also rich and varied, mostly for birds and animals, there are people, landscapes and other patterns, rich life and decorative beauty. At the same time have influenc of literati culture , the Song Dynasty arts and crafts show elegant beauty of the literati, to show its refined subtle S elegant style.

Throughout the Tang and Song dynasties porcelain, silk, clothing, lacquerware, furniture and other arts and crafts, political, economic, philosophical, cultural and aesthetic trends and other factors determine its aesthetic value. Tang Dynasty arts and crafts emphasis "emotion" ,the style is romantic and unrestrained, elegant, magnificent broad; Song Dynasty art style to "reason" for the art: strict dignified, elegant , fresh and graceful.

Tang and Song brilliant craft culture, integration of the north and south, infiltration of ancient and modern, blend of Chinese and foreign, on the future development of arts and crafts had a huge impact, is two bright pearls of the chinese arts and crafts history.

\section{References}

[1] Cao Yiqiang "Art and History", China Academy of Art Press, 2001

[2] Xu Fuguan "Chinese Art Spirit" Shanghai East China Normal University Press, 2002

[3] Wang Haixia. Folk Arts and Crafts [M]. Beijing: China Social Press, 2008: 25,38

[4] Yin Dingbang. Introduction to Design [M]. Changsha: Hunan Science and Technology Press, 2006: 236,238

[5] Thin Song years. Chinese art history tutorial [M]. Xi'an: Shaanxi People's Fine Arts Publishing House, 2000: 369,372,374

[6] Richard Buchanan. Zhou Dandan. Discovery Design [M]. Nanjing: Jiangsu Fine Arts Publishing House, 2010: 19, 21 